\title{
The Allure of Being Modern: Personal Quality as Status Symbol Among Migrant Families in Shanghai
}

For citation:

Tian, Xiaoli. 2019. "The Allure of Being Modern: Personal Quality as Status Symbol Among Migrant Families in Shanghai" Chinese Sociological Review. 51(3): 311-335

\begin{abstract}
:
This paper examines how the powerful suzhi (personal quality) discourse affects the subjective understanding of Chinese migrant workers towards their situation in the city in order to elucidate the micro-level processes that the lower social class acculturate to the dominant cultural capital. Many migrants from the Chinese countryside have remained in Shanghai despite that in doing so, their children are prohibited from taking senior high school and college entrance examinations. In two waves of interviews with migrant parents and children over a 10-year period, parents have justified their decision to remain in the city, reasoning that their children adopt "modern" habits, behaviors and lifestyles which render them "modernized", and thus elevate their social status even without a higher education. Cultural discourses with strong connotations of authority and power provide the framework that the migrants use to improve their relative social status at the micro-level. This research foregrounds the consideration of relative social status in decision-making and social behavior as a micro-process through which the lower social class subscribes to a cultural discourse that reduces them to a lower position.
\end{abstract}

Keywords: acculturation, status symbols, suzhi discourse, internal migration, China 


\section{Introduction}

The concept of cultural capital is important for understanding the impact of culture on social reproduction. Bourdieu argued that cultural capital is used by the dominant class to make distinctions and perpetuate their domination over the lower social classes (Bourdieu 1984). As such, would the lower social class also subscribe to the legitimacy of the "legitimate high culture"? Current literature offers two approaches to answering this question; one subscribes to the cultural hegemony approach per Bourdieu (1984), which argues that the culture of the higher social classes gain legitimacy through institutions such as education. The second approach is based on American society and argues that the lower social classes do not necessarily accept the ultimate legitimacy of the dominant cultural capital of the higher social classes (Lamont and Lareau 1988). Nevertheless, both approaches are credible and apply to different societies (for example, France versus the U.S.). However, even findings from the U.S. confirm that the dominant cultural capital still has a major influence on the underclass. Although many of the poor and underclass develop non-dominant cultural capital, which helps them to build their selfidentity and a sense of community belonging, they still do not reject the dominant cultural capital (Carter 2003). So, why would the dominated social classes subject themselves to the dominant cultural capital? At the individual level, how exactly does the dominating cultural discourse influence subjective understanding and consequently life choices?

This paper examines the influence of a powerful cultural discourse, i.e., the suzhi (personal quality) discourse, on the subjective understanding of migrant families about their urban situation in contemporary China. Suzhi discourse stems from the last days of the Qing dynasty and has been most recently promoted by the state after the economic reforms in the 1980s. Advocated by the Chinese state as a "human modernization" program, and the Chinese 
governing elite as "improvements in personal qualities", the suzhi discourse stipulates the value and criteria of the good, bad, prestigious and undesirable. This powerful discourse discriminates against rural people; yet rural migrants embrace this discourse as one of the reasons to stay in the city.

Millions of migrant families who reside in large Chinese cities like Beijing or Shanghai have to decide whether to stay or leave because their children do not have local household registration (hukou) and therefore cannot participate in city high school or college entrance exams. ${ }^{1}$ To many migrants, a higher education is the only means for their children to achieve intergenerational upward mobility, but they would have to return to their hometown. Although some families have gone back to their hometown, many have chosen to stay in the city even though their children who have a rural hukou status cannot access higher education, and thus in many cases, resort to low-end jobs (Woronov 2011).

The extant literature has mainly focused on the return of migrants to their hometown or smaller cities in their home provinces (Fan 2011; Tang and Hao 2018). They attribute this decision to leave the large cities to rigid structural and institutional constraints, such as the hukou system and unfair educational policy (Wu 2011; Lan 2014; Xiong 2015). However, relatively little research has been done to examine why many migrants and their children stay despite the structural constraints. Most importantly, none have sought to understand how migrants selfperceive their situation or that of their children. How do migrants justify relinquishing a higher education for their children, which is arguably the most important channel for their children's upward mobility?

To understand their decision, this study draws on two waves of in-depth interviews with migrant workers and their children over a period of ten years. The investigation focuses on 
Shanghai, a city considered to be the most modern with the highest modern cultural authority in China (Chew 2003). In-depth interviews reveal that rural migrants mobilize the suzhi discourse through which they acculturate into the Chinese urban culture to justify their decision to stay in Shanghai long-term.

The acculturation process requires individual consideration of relative social status, and suzhi discourse provides measures for both self-evaluation and the evaluation of others. This discourse allows "quality" to be evaluated (something which is normally considered difficult to do), but it considers migrants to be "low quality". Despite the discrimination of this discourse against them, the migrants still adopt the prescribed "good personal qualities" of the suzhi discourse because they recognize that doing so is the only way to elevate their social status.

To increase their relative social standing among rural hometown peers, the migrants choose to live in Shanghai which, according to the suzhi discourse, provides opportunities to become more "modern (xian dai)" and "cultured (you jiaoyang)". Being "modern" means acclimating to an urban lifestyle, such as adopting modern mannerisms (limao) and having better personal hygiene (jiang wei sheng). There is also the belief that it is more favorable for children to be in Shanghai even without a high school education because they are exposed more to a "modern" lifestyle that nurtures "modern" virtues, such as having broader horizons, being polite and stylish, and so forth. Therefore, in a society with rigid structural constraints, rural migrants focus on "becoming modern" in order to raise their social standing in the suzhi hierarchy.

In the sections that follow, I first discuss the relevant literature on cultural capital, status, quality, the rural-urban divide in China and suzhi discourse. After providing details on the methodology and means of data collection, I then show how rural migrants and their children understand the benefits of staying in Shanghai. Next, I discuss their adoption of "modern" 
qualities by staying in Shanghai, and how this internalization of "modern" values and lifestyle influence their understanding of their relative social status.

\section{CULTURAL CAPITAL AND SYMBOLIC BOUNDARIES}

Bourdieu (1984) emphasized the importance of status symbols in culture, lifestyle, and practices. Cultural capital is based on economic capital and acts as an intermediary for the transmission of class differences between generations, which consequently reproduces social inequality. According to Bourdieu (1984), the consumption of art or other cultural products is a predisposed action that aims to legitimize social differences. The hierarchy of "taste" produces gaps between different social groups, and the aesthetics hierarchy, intentionally or unintentionally, maintains distance between different classes. Power hierarchies are created by conceptual distinctions that are produced for both inclusionary and exclusionary purposes, resulting in symbolic boundaries. Once these boundaries are constructed, they are used to justify different values of moral worth at both the individual and collective levels, with some of these values having more merit than others.

The most important insight into the theoretical framework á la Bourdieu is that the lower classes accept status symbols and subscribe to the cultural capital of the higher social classes because they cannot define the legitimate culture. This is the cultural hegemony argument: the higher social classes exercise their power and control by legitimating the superiority of certain cultural norms and practices, and incorporating them into formal institutions such as educational systems (Bourdieu 1974[1966]). In this way, the preferences and practices of the higher social classes are normalized, and they ultimately regulate behavior and control access to resources (Bourdieu and Passeron 1977[1970]). 
However, empirical research, especially when conducted in the U.S. context, shows that disadvantaged social classes do not always accept middle-class status symbols as those of higher status. Lamont and Lareau (1988) found that consensus towards high status cultural signals is weak and uncertain in the U.S. as opposed to France. In the U.S., frequent cultural innovation and transgressions between cultural genres and styles make symbolic boundaries between "legitimate" and "illegitimate" cultures more blurred. Small, Harding and Lamont (2010) further pointed out that different tastes, habits, and styles are privileged by different social classes. In his classic study on working class young people, Willies (1977) found that workers maintain a sense of superiority and reject middle-class values and careers, even though this false consciousness perpetuates their subordinance. Similarly, in poor minority communities in the U.S., music and clothing style preferences and speech patterns that differ from those of high cultural capital facilitate peer group membership (Carter 2003). This means the lower social classes might have autonomy and do not necessarily accept the mainstream cultural capital transmitted by the middle-class.

To be sure, the empirical findings on U.S. ethnic minority groups are valid within the American context. In the Chinese context, those children from social-economically advantaged families are also more likely to have greater cultural capital ( $\mathrm{Hu}$ and $\mathrm{Wu}, 2019)$. Then the question that follows is, could Chinese migrants have the kinds of cultural autonomy like the low-income African Americans in the U.S. study? Also, while the poor and working class in the U.S. may not always accept the dominant cultural capital, they do not reject it either (Carter 2003). In fact, it is common for the poor to define themselves as close to being mainstream or part of middle class society. For example, fast-food workers in Harlem, New York consider themselves morally superior to the unemployed poor (Newman, 1999), and "decent" families in 
a Philadelphia ghetto distinguish themselves from "street" families on the basis of their employment in the formal labor market; discipline of their children; and avoidance of deviant behaviors (Anderson 1999). That is to say, the underclass also self-perceive a higher relative social status by comparing themselves with other underprivileged groups.

How and why do lower social classes adopt status symbols or cultural discourses that have relegated them to a lower position? And what are the micro-level processes that individuals use when considering relative social status? This paper offers a useful alternative to answers provided in existing literature by focusing with a different lens-Individuals, even lower social classes, can achieve relative social status by adopting the qualities defined by a powerful cultural discourse.

\section{STATUS COMPETITION AND SOCIAL BEHAVIOR}

Status is usually defined as the collectively shared assessments of relative social standing that is evaluated on the basis of individual characteristics such as income (see Webster and Hysom 1998; Mark, Smith-Lovin, and Ridgeway 2009). Status affects how people are evaluated, rewarded, and accorded influence in daily life (Ridgeway and Walker 1995; Correll and Ridgeway 2003).

As such, status competition very much governs social behavior (Ermer, Cosmides \& Tooby 2008). Hamilton (1977) described how individuals' membership or aspirations of membership in a "status group" per Weber (1968:937) influence their perceived social desirability of specific ideal and material goods. From this perspective, consumption is directly related to not only one's social status, but also his/her efforts to substantiate that status by consuming particular life style. Moreover, studies of behaviors such as bullying among prison 
inmates (South and Wood, 2006) and risky decision-making (Ermer, Cosmides and Tooby, 2008) affirm the social comparison theory á la Festinger (1954), which suggests that people's self-evaluation of their own opinions and abilities is based on comparison with others (Wood, 1989).

For example, lower social classes tend to show strong outgroup favoritism towards higher status groups and even identify with them (Jost, Banaji and Nosek 2004). Related to outgroup favoritism is upward comparison: the constant comparison of one's own values and lifestyle with those of the higher class. In doing so, the subjective understanding of one's relative social standing is based on the meaning construed from daily performance rather than as a response to structural inequality (Alicke et al. 1995; Collins 1996). One example of this is Sanskritization in the Indian caste system, where lower caste members collectively attempt to adopt the customs, practices and beliefs of higher castes, and give up customs that are shunned by the higher castes to seek upward mobility (Srinivas 1952).

This process of seeking upward mobility through upward comparison and self-acclimation is best illustrated through the sociological notion of "passing". Passing is the act of putting on cultural performances to masquerade as a member of another social group, usually one of higher social status (Drake and Cayton 1945; Goffman 1963; Renfrow 2004), by imitating the characteristics of the more advantaged class (Orne 2013) and using their attitudes, customs and rituals as standards to evaluate behavior. The norms and attitudes of the prestigious class are adopted in hopes of gaining entry as members into the perceived higher social groups. Passing is especially common when there is a conspicuous stigma against a particular social group.

Of course, certain "qualities" are necessary in order to pass. While qualities such as political capital (power) and economic capital (money) are important bases of status distinctions, 
cultural capital is also important because status distinctions are rooted in shared values, or similarities and differences in conceived values (Mills 1963[1954], Veblen 1994[1899]).

Distinctions are communicated through status symbols, which are used as boundary markers to differentiate different statuses (Sauder 2005). An important status symbol is cultural taste, which is used to differentiate one from the "others" (Edelmann and Vaisey 2014). In this paper, I will show how the consideration of relative social status by migrants acts as an intermediate factor that facilitates their acculturation to the personal quality as defined by the suzhi discourse, and consequently influences their decision to stay in the city.

\section{URBAN-RURAL HIERARCHY AND SUZHI DISCOURSE}

Studies of stratification and social mobility in China have highlighted the culturally construed urban-rural divide (see Cheng and Selden 1994; Cheng and Dai 1995; Wu and Treiman 2007; Whyte 2010), which is economically defined with an urban-rural income ratio as high as 3:1 (Whyte 2010). In daily social life, rural dwellers are poorly regarded for all their attributes, particularly their mannerisms and physical appearance. This devaluation is promoted by the powerful discourse on suzhi (Lan 2014), which attributes the failure of modernization in China to the "lack of quality" of its population, especially the rural citizens (Anagnost 2004:190). Thus, to the governing elite, improving the suzhi of the massive rural population is vitally important for China to become a competitive global player (Yan 2008).

Although never clearly defined, suzhi often refers to "the innate and nurtured physical, intellectual and ideological characteristics of a person” (Murphy 2004:2). More specifically, suzhi refers to a modernized way of thinking and living which involves attributes that allow individuals to compete and succeed in modern society. Like suzhi, the term "modern" (xiandai) 
has never been clearly defined, but is often used as a contrast to the "peasant mentality" (nongmin yishi) (Yi 2011). Consequently, two major movements that promoted the dissemination of the suzhi discourse emerged in the 1980s, namely, family planning which focused on the "suzhi of the entire population" and "suzhi education" which targeted students. Their purpose was to cultivate more high-quality citizens and accumulate "human capital" to enhance China's power in the market economy and global competition (Sigley 2009, Jacka, 2009: Anagnost 2004). During this process, those considered to have less quality invited more scrutiny (Murphy 2004:3), even though the suzhi discourse involved everyone. The target groups were naturally those who lacked suzhi, such as peasants (Murphy 2004, Yi, 2011) or migrant workers (Yan 2003a, 2003b).

However, other social groups were not exempt from the suzhi discourse. Tomba (2009) found that the state focused on cultivating the suzhi of the middle class. They were not only supporters of the discourse but also examples of those with "high suzhi"; ideal citizens who did not challenge political authority but maintained social stability and core values, and promoted "high suzhi" through morality and values. Therefore, suzhi has evolved into physical politics and its discourse has reconstructed the values of a group of people so that they have different values. Suzhi is manifested as both urban citizens who want their children to gain entry into the middle class and migrant workers who want to remove traces of their peasantry (Anagnost 2004).

Its long history and ardent support from both the state and cultural elites reflect the high cultural authority of the suzhi discourse, and thus, it is immune from criticism. Therefore, it is imperative to increase one's suzhi, which is realized through suzhi jiaoyu ("quality education"). Suzhi jiaoyu are methods of teaching that cultivate inner qualities for human modernization (ren 
de xiandaihua) (Yi 2011). Thus, suzhi jiaoyu emphasizes creativity, civic responsibility and overall personal development.

\section{TO RETURN OR STAY: DILEMMA OF RURAL MIGRANTS}

A potential means for rural individuals to overcome the urban-rural divide is to migrate to the cities for employment. Indeed, the market reform in 1978 lifted the ban against rural-to-urban migration and large numbers of migrant workers flocked to the cities. However, they still retained their rural hukou and were thus ineligible for most high status jobs, full citizenship rights and benefits enjoyed by urbanites (Whyte 2010). In large cities, like Shanghai and Beijing, migrant children are still required to return to their hukou for high school and college entrance exams. $^{2}$

Many institutional factors have been identified as the main constraints that pose challenges to the settlement of migrant families in large cities; for example, the hukou system and unequal access to urban resources and social welfare (Xu, Guan, \& Yao, 2011; Ye \& Wu, 2014), and routine discrimination against rural migrants (Chan \& Buckingham, 2008; Lu \& Song, 2006; Nielsen \& Smyth, 2011; Wang \& Fan, 2012; Xu et al., 2018).

As a result of these institutional constraints, most rural migrants do not intend to settle permanently in their host city (Fan 2011). There are both pull and push factors for return migration: the institutional and social constraints in the city push them to return, and family needs associated with marriage, childbirth, and caregiving often pull rural migrants back to their home of origin (Wang \& Fan, 2006; Zhao, 2002). However, most of the migrants do not really want to go back to rural hometown. Instead, many are inclined to go to a local town or city in their home region rather than back to their rural origins (Tang and Hao 2018). 
The return migration phenomenon has been the subject of much discussion in recent years, yet relatively little is known about those who do end up settling in the cities or staying there for decades. Even if they are statistically a smaller group compared to the circular migrants and split households (Fan 2011), they are theoretically important for understanding the acculturation processes. Given the recent empirical studies that suggest a high prevalence of failure migrants among return migration (Wang and Fan 2006), migrants who stay in the city for the long-term are likely to be those with more economic and cultural capital.

However, if they stay, their children can either attend vocational school or work, neither of which results in high status jobs or an urban hukou (Ling 2015). Instead, they perpetuate the underclass by reifying the social hierarchy with migrant workers at the bottom (Woronov 2011, Xiong 2015). How, then, do migrant workers justify their decision to stay in the city at the cost of formal educational opportunities for their children? $?^{3}$

\section{DATA AND METHOD}

To answer this question, fieldwork was conducted primarily in the Minhang district in Shanghai at an average public middle school. This is a school that is situated towards the middle amongst school performance. It is neither a top school, nor the lowest on the rung. This school was established 44 years ago and has about 320 students from Grades 6 to 9. There is about an equal number of migrant and local children, who are segregated, but use the same textbooks and curriculum. With a few exceptions, all the teachers are local Shanghainese with a college degree.

The first wave of semi-structured, in-depth interviews was conducted between March 2006 and January 2008, usually at the residence of an informant by a research team with members from Shanghai, Hong Kong and the U.S. None of the team members spoke Shanghainese. There 
were separate hour-long interviews for the children and their parents conducted in Mandarin, so that they would not overhear each other. In total, 62 respondents from 25 families were interviewed, and half were interviewed twice. In addition, the interviewers observed and took notes on their living conditions (size of rooms, cleanliness of the house, and such). The interviews were transcribed by research assistants and coded by the author.

Shanghai was selected as the field site because it is the most modern city in China and has more cultural authority in terms of being modern and cosmopolitan than any other Chinese city (Chew 2003). Many migrant families in this study owned a business, ranging from petty businesses with an approximate monthly revenue of RMB 3000 to large businesses that bring in about RMB 40,000 monthly. Some parents are white-collar employees. Many of the migrant families had lived in Shanghai for a long period of time, some of them for decades, and thus their children could be considered "native" as they speak fluent Mandarin with no rural accent, which distinguishes them from the children of their hometown. Their lengthy residence meant that they had frequent contact with locals and exposure to the "superior" urban culture.

It is important to note that this is not a representative sample. My aim is not to apply the research findings of this study to all migrants or the majority of migrants in China. Rather, the families in this study are not very typical: they have resided in Shanghai for a long period of time. Many of them have many other family members in Shanghai. They have made the decision to stay while many others have returned. They also have many opportunities on a daily basis to come into contact with Shanghai locals. So, while this is not a representative sample of rural migrants in China (the majority of migrants work in construction sites, factories or the service industry in Shanghai), their characteristics make them ideal for studying acculturation in a cultural discourse that discriminates against them. 
All 37 students between 12 and 17 years old in the sample were migrants with a rural hukou at the time of the interview. They ranged from top students to those at the bottom of the class. The number of males and females were about the same. Two were born in Shanghai while the rest in a rural town, mostly from the major migrant-sending provinces such as Anhui, Henan, and Jiangxi, but left for Shanghai at a young age. A few studied for one or two years in their hometown. Seventy per cent have been in Shanghai for over six years. Sixty per cent have siblings.

The parents ranged from 33 to 58 years old at the time of the first wave of interviews. Their education level ranged from illiterate (30 per cent) to high school (two fathers), with the majority having a primary or a middle school education. None had a college degree. Out of the 25 families, 16 operated their own business, which ranged from selling items like fish at the local market to operating a small logistics company. The remainder worked in the service sector, such as driving a taxi. Their monthly family income ranged from RMB 2,000 (USD 306) to over RMB 40,000 (USD 6,700). ${ }^{4}$ Seventy per cent made between RMB 3,000 (USD 460) and RMB 5,000 (USD 766) per month in 2006. ${ }^{5}$ There were some exceptions: two families had higher monthly incomes of RMB 20,000 and 40,000; both were business owners and doing well financially. With a few exceptions, they lived in low-rise (pingfang) rented houses, usually old and poorly maintained in industrial areas. Often the entire family shared one to two rooms with only basic amenities. However, their dress was similar to that of their urbanite peers of the same income level. None spoke the Shanghai dialect, although those who had been in Shanghai long enough could understand it.

A few patterns emerged from the first wave of interviews. First, even though both parents and children were frustrated by the policy that did not allow migrant students to continue their 
studies in Shanghai, and despite the serious discrimination that migrant workers face, almost all stated that they have gained more than lost by moving to Shanghai. Second, regardless of their economic situation, all emphasized their gains in terms of "broadened horizons" (jian shi guang) and "improved personal quality" (suzhi tigao le). In fact, some stated that they could earn similar wages in their hometown but prefer to live in Shanghai as higher quality citizens (gao suzhi). Also, their children are polite (guai) and obedient (tinghua) with good habits (xiguan hao), while children in their hometown are wild (ye) and uncivilized (bu wenming).

These findings compelled the implementation of the second wave of interviews, in which there was more focus on the influence of the suzhi discourse on how the migrants subjectively understood their situation in Shanghai. From December 2014 to March 2015, 26 parents and children from 12 families were interviewed. Six families were from the previous sample because they were still in the area and agreed to the interviews. The other six were families who resided in a nearby neighborhood with similar backgrounds and characteristics: many were small business owners, and their children attended the same school as Shanghainese students. The purpose of these interviews was to examine in more detail their views on relative social status, and the evaluative criteria that they used to judge social status.

Surprisingly, although 10 years had lapsed and Shanghai had changed immensely, the responses were similar to those in the first wave of interviews. The interviewees felt that their personal qualities have improved after living in Shanghai, and that in itself is enough. The fact the two waves of interviews provided similar responses shows that a more cultural and physiological process underlies the life choices of the migrants rather than merely external push or pull factors. While external structural factors are important because they make life choices possible, it is still important to know how migrants as individuals understand or justify their life 
choices at the micro-level. In response, I decided to examine how the suzhi discourse influenced the subjective understanding of the migrants of their conditions and life choices.

\section{GAINING STATUS BY BECOMING A MODERN PERSON}

The findings from both waves of interviews on why migrants decide to stay in Shanghai or return to their hometown are consistent with those in existing research in that they had considered sending their children back, but felt that it is unrealistic for many reasons such as financial obstacles and the low quality of rural schools (see Lan 2014; Ming 2014; Ling 2015; Tian 2017). Consequently, among the 37 students in the first wave of interviews, only four eventually returned to their hometown for high school. ${ }^{6}$ The rest remained in Shanghai and either attended a vocational school or withdrew from school to work in low-end jobs. There is no reliable largescale quantitative data on the percentage of migrant children who stay in the city or withdraw from school. However, other qualitative studies show that only around 10 to 15 per cent return to their rural hometown (see Koo 2012). Nonetheless, the jobs that they acquire in the city are low in income, skills, and prestige. How, then, do the parents and children understand their future in the city? Or, how do the parents justify this decision?

The migrants expressed frustration towards the education policy, which they considered the greatest obstacle to settling in Shanghai (see also Tian 2017). Nevertheless, they considered their experience and future in Shanghai positive because they have "improved their suzhi". Both parents and children felt that they would continue to self-improve if they remained in Shanghai, where they would be exposed to modern civilization and assimilate by emulating the modern style, behaviors, quality education, and views of the local Shanghainese. 
Although the interviews were conducted almost a decade apart, the perceptions from both waves of interviews are largely the same in that the personal qualities, including polished style and polite behaviors, are modeled after the locals:

My biggest achievement in Shanghai is broadening my horizons... I meet all kinds of people. When I visit other people at their home... the setup and furniture [are] stylish... For example, I visited a teacher at her home... She has a really nice cabinet... When I have my own place, I will get the same thing... (Wave 2, Case 9, mother, cab driver, 8 years in Shanghai, income RMB 5,000)

The "teacher" here is actually a university faculty member who was neither born nor raised in Shanghai; however, she still exemplified being "Shanghainese". She is perceived as Shanghainese because of the cultural capital she has. Her stylish home décor and Shanghai hukou make her a "modern" Shanghainese. In fact, the respondents often used the term "Shanghainese" broadly, but exactly what qualifies as "Shanghainese" is debatable. In many cases, the interactive other was not born in Shanghai nor did they grow up there. Rather, they might be university graduates from other provinces who went to Shanghai to work and have gained Shanghai hukou. Nevertheless, the migrants consider them to be "Shanghainese" and "local".

The respondents also admired the Shanghainese lifestyle as urban and more civilized, which they tried to imitate:

The Shanghainese have colorful lives... They go to movies and bars... Whatever they have, I also want for my children... such as more education in the arts and music... a quality education. (Wave 1, Case 5, father, fishmonger, 20 years in Shanghai, income $\operatorname{RMB} 3,500)$ 
In addition to being convinced that imitating modern lifestyles and education cultivates suzhi, the migrants also seek to improve interpersonal skills and behaviors. This is a conviction that even the children have internalized:

I've been to the Bund (wai tan), the city temple and so on... Also, I'm more polite now, I have better manners and better personal hygiene. The Shanghainese are liberal and open, easy to socialize with. They talk with a soft voice. Not like people in my hometown... Now I act and behave much more like the Shanghainese students. (Wave 1, Case 18, child, $8^{\text {th }}$ Grader)

Local students are very different from non-local students. They are very polite, have better personal hygiene... Perhaps it's easier to make friends with non-locals but I'd rather be friends with locals so I can learn from them. (Wave 1, Case 13, child, 12 years in Shanghai)

During the interviews, I specifically asked the children about their playmates. Although they experienced difficulties in fully integrating with the local students and spent more time with other migrant students, half of them preferred friendship with local students because they could improve their personal qualities, and they did have local Shanghai friends. They would avoid friendship with students from their hometown, citing excessive differences.

Despite the barriers to a higher education, many parents still felt that their children benefited from activities in their primary school education that are usually unavailable in rural schools. These included music, sports, arts, and field trips that constituted "quality education" (suzhi jiaoyu) (Yi 2011) because these provided life experiences, knowledge, and "broadened horizons". "Quality education" was only considered relevant to metropolitan cities such as Shanghai and implemented better there. ${ }^{7}$ 
In Shanghai, my daughter has learned to dance, play music, sing, and draw at school. But the children in our hometown don't do any of those things. (Wave 1, Case 8, housewife, income RMB 5,000)

Other quantitative research also confirms that migrant children do benefit from better educational recourses in the cities (Xu and Dronkers, 2016; Xu et al., 2018). In addition to engaging in the activities that constitute a "quality education", the migrants adopted the positive views and stances of the Shanghainese, reasoning that even if Shanghai is widely known as a city that discriminates against non-locals (Lan 2014), discrimination only occurs if they do not adopt the behaviors and urban habits of the Shanghainese:

I have met the local Shanghainese... and... never felt discriminated against. That's because I behave myself, so others wouldn't have a chance to say anything bad about me. I think that the Shanghainese are smart, diligent and capable. (Wave 1, Case 9, father, truck driver, 14 years in Shanghai, income RMB 5,000)

Other studies have found that those migrants who have more frequent interactions with others in the city actually have weaker settlement intentions because the migrants might feel discriminated during the interactions, consequently reinforcing their marginalized positions (Fan 2011). However, in this study, migrants who have more frequent interactions with others in the city express strong settlement intentions, probably because they think that they have adopted urban habits that will give them future opportunities in the city. Thus, even if the Shanghainese did discriminate against the non-locals, it is because:

The non-locals... need to change their bad habits. That's why they're being called country bumpkins. The Shanghainese say that non-locals have poor hygiene... In the rural villages, kids poop on the streets and sometimes they do that even after coming to 
Shanghai... But you know, that's wrong... Non-locals have a lot of children... but the more children you have, the poorer your family becomes... (Wave 2, Case 1, father, illegal cab driver, 13 years in Shanghai, income RMB 4,500)

Poor hygiene and large families are apparently deserving of discrimination because they justify the perception that migrants are not modern or civilized ${ }^{8}$. To be sure, personal hygiene and politeness have functional value. However, in the interviews, the respondents point more to their symbolic rather than functional value.

Since the respondents are all ethnic Chinese, there are no physical differences from the Shanghainese, except for their attire. As such, by adopting the styles, behaviors, and viewpoints of the Shanghainese, they can pass as locals if they perform their roles well. Most interestingly, all of the migrants considered themselves more like the Shanghainese and when they returned to their hometowns, others also saw them as Shanghainese:

Now when I go back, people... think I look like a Shanghainese... Me too, because my character, personality, and behavior are very different from the [other children] in my hometown. (Wave 1, Case 11, child, 7 years in Shanghai)

Of course, the migrants would never actually pass as urbanites due to structural barriers. Nevertheless, faking to pass as a local is still important. The benefits of seemingly passing or the potential to pass creates validation. For instance, they felt validated when they hosted visitors from their hometown and navigated Shanghai like a local, which subsequently increased their relative status.

The respondents also offered little resistance to the discourse of Western-influenced modernity, even though this discourse positions them as less valuable. In the U.S., low-income African American youth would reject the dominant culture (Carter 2003). Yet this is not the case 
with the migrants in China. The Chinese migrants (even those with capital) did not participate in defining their own meaning of modernity, and thus their elaborations on what "modern quality" meant to them echoed the official discourse. This lack of resistance to the suzhi discourse is validated by other studies; for example, Yi (2011) found that teachers in a Xiamen school attributed negative characteristics to rural children, yet most parents blamed themselves for their lack of educational capital to increase the suzhi of their children. Murphy (2004) also found that parents usually accepted the labelling of children as having low suzhi. Li (2005) found that even though migrant youth did not accept that they have low suzhi and only mentioned suzhi in their prejudiced comments about rural people, they nonetheless accepted the overall legitimacy of the suzhi discourse. This lack of resistance is prevalent because the cultural power hierarchy cannot be defeated without the proper institutions or adequate powers in place to contest it (Chew 2003). Migrants have neither institutions nor power and thus can only accept and attempt to acculturate to the hierarchy.

In theory, there are alternative forms of modernity, and there is likely to be resistance against the cultural hegemony. However, these were not evident among the migrant families in this study based on the data. This lack of resistance and the fact that they embrace a discourse that discriminates against them are compelling. For example, "tanned" skin could be a sign of rural backwardness or affluence, with the former signifying physical labor outdoors and the latter exotic vacations. However, among the migrants in this study, tanned skin is dominatingly the former. The process is still rather one-way and unidirectional, probably because this is their best strategy to maximize their status: focusing on their achievements in Shanghai, and emphasizing their relative advantages compared to their rural counterparts. 


\section{GAINING STATUS THROUGH IMPROVED SOCIAL STANDING}

The migrants left for Shanghai to seek a better life with a higher income and social status relative to their reference groups. When they returned home, their fellow villagers were considered less civilized when evaluated against the modern qualities in the suzhi discourse, which increased their relative status. They also commended themselves for abandoning rural practices and behaviors, thus elevating their own perceived social status, and concluding that they and the Shanghainese are superior:

In my hometown, people... fight over small things. The Shanghainese rarely do that. People in the countryside gossip... They speak loudly and are abrupt... When I go back... they pass me stuff and I say, "thank you"... They'll reply, "So you are a Shanghainese now..." Now that I've lived in Shanghai... I've become a much better person. (Wave 2, Case 10, mother, domestic worker, 5 years in Shanghai, income RMB 6,000)

When I went back to my hometown with my parents for Chinese New Year, I saw people spitting everywhere. We never do that in Shanghai. We're much more civilized than them. (Wave 1, Case 23, child, $9^{\text {th }}$ grader, 15 years in Shanghai)

The parents especially reveled in comments from their fellow villagers such as, "here comes the Shanghainese", or "here comes the little Shanghainese", which gave them status because it insinuated that they are "someone from the big city". Chew (2003) illustrated the hierarchy of cultural authority in contemporary China: Westerners have the highest authority, then the Shanghainese. Thus, when the migrants returned to their hometown, they have a higher social standing and authority through affiliation. 
Certainly, the perceived higher status is also because these migrants have more economic capital from working in Shanghai. As Bourdieu (1986) observed, economic capital is the root of cultural capital; however, the emphasis in the interviews was more on suzhi than income. Thus, status symbols were more emphasized as status markers than economic capital itself. The interviewed parents also felt that their children excel over the children from their hometown in all aspects:

In my hometown, the children... all look like hoodlums. They cuss and swear. My son is educated here, so he is... civilized and polite.... The children in my hometown know nothing about quality or brands... But my son knows how to play and use electronic devices and the computer... He would choose to use brand name products... (Wave 2, Case 2, father, grocery seller, 9 years in Shanghai, income RMB 6,000) The migrants confess that they attain modern qualities simply through exposure to the "modern" and therefore higher class culture and lifestyle in Shanghai. This exposure is equally as important to the migrant children as enrollment in a Shanghai public school equates to receiving a suzhi education, which is another way to cultivate cultural capital.

Another important reason that parents preferred that their children remain in Shanghai is the fear of losing cultural capital due to engaging in social behaviors considered to be part of a lower class:

I'm afraid of sending her back... Certain environments breed certain types of people. My hometown produces savage and uncivilized people. I don't want my daughter to be like that. (Wave 1, Case 16, father, sales representative, 16 years in Shanghai, income RMB $8,000)$ 
The migrant children also considered their rural peers to have deficient cultural capital and lack access to cultural capital:

Of course I'm different from the kids in my hometown... For example, I've been to many places such as the Pearl of the Orient in Shanghai... People in my hometown don't get to go... (Wave 2, Case 2, child, $7^{\text {th }}$ grader, 6 years in Shanghai)

To many migrants, the status hierarchy is clear (in order of modernization level): rural areas, small cities, provincial capital cities and then large cities (Shanghai and Beijing). A mother compared Shanghai with other provincial capital cities and made it very clear that she felt Shanghai is the epitome of modernity:

I don't want my younger son to work in another city. Our whole family is in Shanghai.

So he has to stay here. My elder son went to work in Hefei last year because his girlfriend is there. I was so mad. Hefei is...nothing compared to Shanghai. How could he sacrifice his own future just for a girl? After living in Shanghai, Hefei is such a step backwards. (Wave 2, case 9)

If someone is already in Shanghai, leaving for a smaller city (Hefei is the provincial capital city of Anhui province) would mean a step down in relative social standing. In other studies, "urban areas in the home region are considered by many prospective returnees as an ideal place to settle down" (Tang and Hao 2018). However, in this study, some families do not even want to consider other capital cities in their home province, as this is equivalent to downward mobility.

In sum, rural migrants, especially migrant parents, tend to think that they have gained much after arriving in Shanghai: better living conditions, more opportunities for economic development, and better human qualities. They consciously use "personal quality" as an evaluative criterion to judge relative social status. When they do so, they consider themselves 
higher in social status than their relatives, friends, and other villagers in their hometown, lower only to the local Shanghainese. Therefore, their relative social standing has been greatly improved by just living and working in Shanghai.

Although the suzhi discourse elevates social status when comparisons are made to rural peers, at the same time, the discourse also reinforces the inferiority of migrants to the locals. While the adults rarely compared themselves to locals, their children often compared themselves to their Shanghai classmates. Since the children grew up in the city and thus have minimal rural experience (Guang and Zheng 2005), they do not compare themselves with rural children. They feel that they are no different from the local Shanghainese children. Consequently, the migrant children want to stay in Shanghai and, like their urban counterparts, aspire to a college education for a future prestigious job, such as an "office job", rather than the low social status or low skilled jobs associated with migrant workers. Thus, their reference groups are the local Shanghainese and other migrant students. During the interviews, around one third of the children indicated that they would like to return to their hometown as early as possible to prepare for the high school entrance exams, and then return to Shanghai for university, as this is the only way that they can compete with their local friends. However, even though children are considered important in Chinese families, many did not return to their hometown because of the considerations of their parents.

Even though the migrant children aspire towards higher education and are thus willing to return to their hometown, few generational differences were found in terms of their suzhi discourse. Both generations expressed their desire to stay in Shanghai, and most importantly, they wholeheartedly embraced the suzhi discourse which they used to evaluate others and guide their own self-improvement. 
The relative social status of the migrants is self-reported. It is not clear the extent that their assumed higher status is recognized by either urban people or those in their hometown. However, given the omnipotence of the suzhi discourse, the perceived higher social status is likely more than self-perception; rather, it is the intersubjective perception of both rural migrants and urbanites. This is corroborated by other research findings that confirm the willingness of urban children to fraternize with second-generation rural migrant children (Ling, 2015), probably because the latter grew up in Shanghai and therefore have higher suzhi.

\section{CONCLUSION}

This paper examines how a group of rural migrants have embraced a self-discriminatory discourse. Consideration of relative status is a micro-level process that links a cultural discourse with individual choices because the suzhi discourse is so powerful and authoritative that face is lost if performance does not meet the rules of conduct. On the other hand, relative status can be gained through higher personal quality and modernization, which improves social standing, based on the guidelines of the suzhi discourse. This discourse gives the grounds for migrants to justify their decision to stay in Shanghai and sacrifice their children's education. They may eventually pass as Shanghainese or their status may increase more than that of their rural peers, perhaps to levels that exceed even the urbanites in their province of origin. In this sense, this study concurs with many of the previous studies that have pointed out the importance of relative social status in decision-making and social behaviors (for example, Hamilton 1977; Wolff et al. 2010).

The cultural capital of these Chinese migrants might be more appropriately explained with the cultural hegemony theory. There is little resistance or autonomy of the migrants, 
especially the first generation, most likely because the suzhi discourse is supported and promoted by a powerful and dominating state. The migrant respondents wholly accept this modernization discourse that characterizes rural people as inferior to urbanites. Modern activities, such as playing music and sports, and modern etiquette, such as speaking in a soft voice and acting in a civilized manner, better personal hygiene, more estranged relationships, untanned skin, etc., are all highly regarded. Not only do they attempt to adopt the persona of a modern person and try to pass as one, but also use "modern" virtues as evaluative criteria to judge others. In this way, they accept the current power hierarchy. The most important consequence of this, of course, is the reproduction of social inequality because migrant children remain disadvantaged. So just like passing, individuals might achieve a higher social status by imitating the performance of the higher social classes, but it remains ambiguous whether this process would lead to structural changes.

This paper focuses only on the subjective understandings of the migrants themselves; how they justify their decision to stay in Shanghai at the cost of their children's education. They draw on the suzhi/personal quality discourse to rationalize an increase in social status by staying in Shanghai. Due to the limited scope of the research, there is no evidence that shows whether others are receptive to migrants' understanding of their relative status, such as their hometown peers or the local Shanghainese. In fact, it is well-known that rural migrants are the targets of intense discrimination in Shanghai. No evidence shows that the Shanghainese recognize how the migrants justify their status, and little empirical research has been done on how other villagers regard migrants who have resided in Shanghai for decades. Despite the limitations in perspectives, it is still valuable to provide a thorough study on the subjective understanding of the migrants themselves, to understand the underlying reasons that compel them to stay in the 
city for such a long period of time, especially when they are facing structural constraints.

Therefore, the main contribution of this paper is its focus on micro-level processes; that is, how migrants justify their choices and the discourses that they rely on to rationalize these justifications.

Even though many of the migrant families live in segregated neighborhoods, the respondents in this study are exceptional in the sense that they are exposed to the "superior" urban culture and many have close contact with the locals. This might be attributed to the fact that many of them work in small businesses. The situation might be different in other places where their children only attend migrant schools or the parents are employed in other industrial sectors such as construction and manufacturing, and are therefore largely segregated from the local urban lifestyle. Nevertheless, the basic argument still holds: decision-making for upward mobility is contingent on the consideration of relative social status, and becoming modern is an important aspect of social status in contemporary China.

This study asserts the importance of symbols and meaning in status processes (Sauder 2005). The power and authority of the suzhi discourse dictate that being modern is an important status symbol in contemporary China. Given the huge economic and cultural disparity between rural and urban China, and also in values and lifestyle, migration to cities (particularly Shanghai) might itself be seen as instrumental to upward mobility. Modern life is not only about participation in the modern production process but also includes resonance with modern values, lifestyles, and behaviors. Perhaps the rural migrants have not really learned how the Shanghainese live their lives, so their understanding of "being modern" is superficial, but the suzhi discourse directs them to subjectively improve their relative social status, and thus justifies their continued stay in the city. 
The migrants accept a particular discourse and align their behaviors with the discourse, which might possibly lead to "better personal quality" and result in a higher social status (success in passing). In this sense, the suzhi discourse does compel modernization of the populace. The outcomes of this "improved personal quality" of the migrants will be worthy of further study in the years to come. For example, what are the positive or negative effects of modernization of the populaces through the suzhi discourse? What is the relationship between perceived personal quality and social status in contemporary China?

\section{ENDNOTES}

1. The 2010 Chinese census states that there are 221 million migrants. Many bring their children with them, which results in an estimated 20 million migrant children (individuals under 18 years old). In 2010, there were 8.98 million non-local hukou migrants in Shanghai-two out of five residents. See: The Population Census Office. 2011. Tabulation on the 2010 Population Census of the People's Republic of China, Retrieved March 10, 2015, (http://www.stats.gov.cn/tjsj/pcsj/rkpc/6rp/indexch.htm)

2. Shanghai has an accumulative point system to determine whether students without local hukou can take higher education exams. This policy came into effect in 2014. If parents achieved a certain number of "points" based on merits, such as occupation and investments in Shanghai, their children can take the examinations. Thus, students with high social economic status can obtain higher education in Shanghai, but not those with low social status (Li 2014, see also Xu and Dronkers, 2016). None of the study respondents benefited from this policy, even those who were financially better off. 
3. Even though both migrant parents and children were interviewed in both waves of interviews, in this paper, I focus on the first generation, because the second generation is a different story. The general embrace of urban cultural capital by the second generation is "natural" because many of them grew up in Shanghai. Also, some of them have developed subcultures as resistance to the dominating suzhi discourse (such as the shamate subculture, even though they are usually harshly ridiculed by mainstream culture).

4. The family income is usually the earnings of both parents and sometimes includes working children (the older siblings of the interviewed children).

5. In Shanghai, the average income of migrant workers in 2013 was RMB 2,476 monthly. If both parents worked, the average household income was around RMB 4,900. See: National Statistical Bureau (Shanghai Investigation Team). 2014. "Ben shi wailai nongmingong shenghuo xiaofei xian'xian shiminhua tezheng" (Migrant workers' consumption in the city resembles that of urbanites). Retrieved March 112015 (http://www.stats-sh.gov.cn/fxbg/201403/267829.html).

6. Those who sent their children back to their hometowns are usually those who 1) could financially afford to do so as one parent needs to accompany the child, 2) have a child who excels academically and will likely perform well in college entrance exams, or 3) have one parent who is convinced that college will give the child and family a better future. The latter are usually individuals with more education, such as high-school graduates. Some parents doubt that college can actually give their children a better future (see Tian 2017). 
7. The lack of suzhi jiaoyu in rural schools is due to limited resources and the rigorous emphasis on traditional studies (see Murphy 2004).

8. The one-child policy in China meant that wanting more children and wanting a son are outdated perceptions linked to rural life. This man only has one daughter but clearly indicated that, after living in Shanghai for years, he now has a modern perspective because he does not strive for a son or more children.

\section{REFERENCES}

Alicke, Mark D., Mary L. Klotz, David L. Breitenbecher, Tricia J. Yurak, and Debbie S. Vredenburg. 1995. "Personal Contact, Individuation, and the Better-than-Average Effect." Journal of Personality and Social Psychology 68(5): 804-825.

Anagnost, Ann. 2004. “The Corporeal Politics of Quality (Suzhi).” Public Culture 16 (2): 189208.

Anderson, Elijah. 1999. Code of the street: Decency, violence, and the moral life of the inner city. New York: Norton.

Bourdieu, Pierre. 1974[1966]. "The School as a Conservative Force: Scholastic Achievement and Cultural Inequalities." Pp. 32-46 in Contemporary Research in the Sociology of Education, edited by J. Eggleston. London: Methuen.

—. [1979]1984. Distinction: A Social Critique of the Judgement of Taste. Cambridge, MA: Harvard University Press.

—. 1986. "Forms of Capital." Pp. 241-258 in Handbook of Theory of Research for the Sociology of Education, edited by J. G. Richardson. Greenword Press.

Bourdieu, Pierre and Jean-Claude Passeron. 1977[1970]. Reproduction in Education, Society and Culture. Beverly Hills, CA: Sage publications.

Carter, Prudence L. 2003. ““'Black” cultural capital, status positioning, and schooling conflicts for low-income African American youth." Social problems 50(1): 136-155. 
Chan, Kam Wing, and Will Buckingham. 2008. "Is China Abolishing The Hukou System?". The China Quarterly 195: 582-606.

Cheng, Tiejun and Mark Selden. 1994. "The Origins and Social Consequences of China’s Hukou System.” The China Quarterly 139: 644-668.

Cheng, Yuan and Jianzhong Dai. 1995. "Inter-Generational Mobility in Modern China." European Sociological Review 11: 17-36.

Chew, Matthew. 2003. "The dual consequences of cultural localization: How exposed short stockings subvert and sustain global cultural hierarchy." Positions: East Asia Cultures Critique, vol. 11, no. 2, pp. 479-509.

Collins, Rebecca L. 1996. "For Better or Worse: The Impact of Upward Social Comparison on Self-Evaluations." Psychological Bulletin 119(1): 51-69.

Correll, Shelley J., and Cecilia L. Ridgeway. 2003. "Expectation States Theory.'Pp.29-51 in The Handbook of Social Psychology, edited by J.D. Delamater. New York: Kluwer Academic.

Drake, St. Clair, and Horace Cayton. 1945. Black Metropolis. Chicago: University of Chicago Press.

Edelmann, Achim, and Stephen Vaisey. 2014. "Cultural resources and cultural distinction in networks." Poetics 46: 22-37.

Ermer, Elsa, Leda Cosmides, and John Tooby. 2008. Relative status regulates risky decision making about resources in men: Evidence for the co-evolution of motivation and cognition. Evolution and Human Behavior 29(2): 106-118.

Fan, Cindy. 2011. Settlement Intention and Split Households: Findings from a Survey of Migrants in Beijing's Urban Villages. China Review 11(2): 11-41.

Festinger Leon. 1954. "A theory of social comparison processes.” Human Relations 7:117-140.

Goffman, Erving. 1963. Stigma. Englewood Cliffs, NJ: Prentice Hall.

Guan, Xinping. 2008. "Equal rights and social inclusion: Actions for improving welfare access by rural migrant workers in Chinese cities." China Journal of Social Work 1(2):149-159.

Guang, Lei and Lu Zheng. 2005. "Migration as the Second-Best Option: Local Power and Offfarm Employment." The China Quarterly 181: 22-45.

Hamilton, Gary G. 1977. “Chinese Consumption of Foreign Commodities: A Comparative Perspective." American Sociological Review 42(6): 877-91. 
Hu, Anning and Xiaogang Wu. 2019. "Science or Liberal Arts? Family Background, Cultural Capital, and College Major Choice in China." British Journal of Sociology 79(1):190213.

Jacka, Tamara. 2009. "Cultivating citizens: Suzhi (quality) discourse in the PRC." positions: east asia cultures critique 17.3: 523-535.

Koo, Anita. 2012. "Is There Any Change to Get Ahead? Education Aspirations and Expectations of Migrant Families in China." British Journal of Sociology of Education 33(4): 547-564.

Lan, Peichia. 2014. "Segmented Incorporation: The Second Generation of Rural Migrants in Shanghai." The China Quarterly 217: 243-265.

Lamont, Michele, and Annette Lareau. 1988. "Cultural Capital: Allusions, Gaps And Glissandos In Recent Theoretical Developments". Sociological theory:153-168.

Li, Miao. 2015. Citizenship Education and Migrant Youth in China. New York: Routledge.

Ling, Minhua. 2015. "Bad Students Go To Vocational Schools! Education, Social Reproduction and Migrant Youth in Urban China." The China Journal 73: 108-131.

Lu, Zhigang, and Shunfeng Song. 2006. "Rural-Urban Migration And Wage Determination: The Case Of Tianjin, China". China Economic Review 17 (3): 337-345.

Mark, Noah P., Lynn S. Lovin and Cecilia L. Ridgeway. 2009. "Why Do Nominal Characteristics Acquire Status Value? A Minimal Explanation for Status Construction.” American Journal of Sociology 115(3): 832-862.

Mills, C. Wright. 1963[1954]. “The sociology of stratification.” Power, politics, and people: The collected essays of C. Wright Mills 305-324. New York: Oxford University Press.

Ming, Holly Ho. 2014. Growing Up in the Urban Shadow: Realities and Dreams of Migrant Workers' Children in Beijing and Shanghai. Unpublished PhD thesis, Harvard University.

Murphy, Rachel. 2004. “Turning Peasants into Modern Chinese Citizens: 'Population Quality' Discourse, Demographic Transition and Primary Education.” The China Quarterly 177: $1-20$.

Newman, Katherine S. 1999. No shame in my game: The working poor in the inner city. New York: Vintage and Russell Sage Foundation.

Nielsen, Ingrid, and Russell Smyth. 2011. "The Contact Hypothesis In Urban China: The Perspective Of Minority-Status Migrant Workers". Journal Of Urban Affairs 33 (4): 469- 
481.

Orne, Jason. 2013. "Queers in the Line of Fire: Goffman's Stigma Revisited." The Sociological Quarterly 54 (2): 229-253.

Renfrow, Daniel G. 2004. "A Cartography of Passing in Everyday Life." Symbolic Interaction 27(4): 485-506.

Ridgeway, Cecilia L., and Henry A. Walker. 1995. "Status Structures.” Pp. 281-310 in Sociological Perspectives on Social Psychology, edited by K. S. Cook, G. A. Fine and J. S. House. New York: Allyn \& Bacon.

Sauder, Michael. 2005. "Symbols and Contexts: An Interactionist Approach to the Study of Social Status.” The Sociological Quarterly 46 (2): 279-298.

Sigley, Gary. 2009. "Suzhi, the body, and the fortunes of technoscientific reasoning in contemporary China." positions: east asia cultures critique 17.3: 537-566.

Small, Mario Luis, Harding, David J., and Lamont, Michèle. 2010. Reconsidering Culture and Poverty. The ANNALS of the American Academy of Political and Social Science 629(1): 6-27.

South, Catherine R., and Jane Wood. 2006. "Bullying In Prisons: The Importance Of Perceived Social Status, Prisonization, And Moral Disengagement". Aggressive Behavior 32 (5): 490-501.

Srinivas, Mysore N. 1952. Religion and Society Amongst the Coorgs of South India. Oxford: Clarendon Press.

Tang, Shuangshuang, and Pu Hao. 2018. "The Return Intentions Of China'S Rural Migrants: A Study Of Nanjing And Suzhou". Journal Of Urban Affairs, 1-18.

Tian, Xiaoli. 2017. “Immediate Context, Life Experiences, and Perception: How Do Rural Migrants in Urban China Perceive an Unfair Policy?” Chinese Sociological Review. 49 (2): $138-161$.

Tomba, Luigi. 2009. "Of quality, harmony, and community: Civilization and the middle class in urban China", Positions: East Asia cultures critique, 17(3): 591-616.

Tower-Richardi, Sarah M., Tad T. Brunyé, Stephanie A. Gagnon, Caroline R. Mahoney, and Holly A. Taylor. 2014. "Living The High Life: Social Status Influences Real Estate Decision Making". Journal Of Applied Social Psychology 44 (9): 611-621.

Veblen, Thorstein. 1994 [1899]. The theory of the leisure class. New York: Dover. 
Wang, Wenfei Winnie, and C Cindy Fan. 2006. "Success Or Failure: Selectivity And Reasons Of Return Migration In Sichuan And Anhui, China". Environment And Planning A 38 (5): 939-958.

Wang, Wenfei Winnie, and C. Cindy Fan. 2006. "Success Or Failure: Selectivity And Reasons Of Return Migration In Sichuan And Anhui, China". Environment And Planning A 38 (5): 939-958.

Wang, Wenfei Winnie, and C. Cindy Fan. 2012. "Migrant Workers' Integration In Urban China: Experiences In Employment, Social Adaptation, And Self-Identity". Eurasian Geography And Economics 53 (6): 731-749.

Webster, Murray Jr., and Stuart J. Hysom. 1998. “Creating Status Characteristics.” American Sociological Review 63: 351-378.

Weber, Max 1968 Economy and Society. New York: Bedminster Press.

Whyte, Martin K. 2010. "The Paradoxes of Rural-Urban Inequality in Contemporary China." Pp. 1-25 in One Country, Two Societies: Rural-Urban Inequality in Contemporary China, edited by M. K. Whyte. Cambridge, MA: Harvard University Press.

Willis, Paul. 1977. Learning to labour: How working class kids get working class jobs. Routledge.

Wolff, Lisa S., S.V. Subramanian, Dolores Acevedo-Garcia, Deanne Weber, and Ichiro Kawachi. 2010. "Compared to whom? Subjective social status, self-rated health, and referent group sensitivity in a diverse US sample." Social Science \& Medicine 70(12):2019-28.

Wood Joanne V. 1989. “Theory and research concerning social comparisons of personal attributes." Psychological Bulletin 106:231-248.

Woronov, Terry E. 2011. "Learning to Serve: Urban Youth, Vocational Schools and New Class Formations in China." The China Journal 66: 77-99.

Wu, Xiaogang. 2011. “The Household Registration System and Rural-Urban Educational Inequality in Contemporary China." Chinese Sociological Review 44(2): 31-51.

Wu, Xiaogang and Donald J. Treiman. 2007. "Inequality and Equality under Chinese Socialism: The Hukou System and Intergenerational Occupational Mobility." American Journal of Sociology 113(2): 415-445. 
Xiong, Yihan. 2015. "The Broken Ladder: Why Education Provides No Upward Mobility for Migrant Children in China." The China Quarterly:1-24.

Xu, Duoduo and Jaap Dronkers. 2016. "Migrant Children in Shanghai: A Research Note on the PISA-Shanghai Controversy." Chinese Sociological Review 48(3):271-295.

Xu, Duoduo, Xiaogang Wu, Zhuoni Zhang and Jaap Dronkers. 2018. "Not A Zero-Sum Game: Migration and Child Well-being in Contemporary China." Demographic Research 38, 691-726.

Xu, Qingwen, Xinping Guan, and Fangfang Yao. 2011. "Welfare Program Participation Among Rural-To-Urban Migrant Workers In China". International Journal Of Social Welfare 20 (1): $10-21$.

Yan Hairong. 2003a. "Neoliberal Governmentality and Neohumanism: Organizing Suzhi/Value Flow Through Labor Recruitment Networks," Cultural Anthropology 18: 493-523;

—. 2003b. "Spectralization of the Rural: Reinterpreting the Labor Mobility of Rural Young Women in Post-Mao China," American Ethnologist 30, no. 4: 1-19.

—. 2008. New Masters, New Servants: Migration, Development, and Women Workers in China. Durham: Duck University Press.

Ye, Lin, and Alfred M. Wu. 2014. "Urbanization, Land Development, And Land Financing: Evidence From Chinese Cities". Journal Of Urban Affairs 36 (sup1): 354-368.

Yi, Lin. 2011. "Turning Rurality into Modernity: Suzhi Education in a Suburban Public School of Migrant Children in Xiamen." The China Quarterly 206: 313-329.

Zhao, Yaohui. 2002. "Causes And Consequences Of Return Migration: Recent Evidence From China". Journal Of Comparative Economics 30 (2): 376-394. 